\title{
Differential Game for Environmental-Regulation in Green Supply Chain
}

\author{
Yenming J Chen ${ }^{1}$ and Jiuh-Biing Sheu ${ }^{2}$ \\ ${ }^{1}$ National Kaohsiung 1st University of Sci \& Tech \\ ${ }^{2}$ National Chiao Tung University \\ Taiwan
}

\section{Mission}

This paper demonstrates that a proper design of environmental-regulation pricing strategies is able to promote Extended Product Responsibility for green supply chain firms in a competitive market. A differential game model comprising Vidale-Wolfe equation has been established in light of sales competition and recycling dynamics as well as regulation related profit function. Analytic solutions of Markovian Nash equilibriums are provided with the necessary condition derived from Hamilton-Jacobi-Bellman equations. We found that governments should opt to gradually raise regulation standards so that rational manufacturers will gradually improve its product recyclability, and, in turn, Extended Product Responsibility will get promoted.

\section{Background and the importance}

Competitive strategies for firms and environmental regulations for governments jointly play an important role in dictating the success of implementing Extended Product Responsibility (EPR) policies (Chen \& Sheu, 2009; Reijnders, 2003). At the same time, strategic management has long been considered a significant part of business competitiveness. Most of existing reports, however, concentrate only on the impact of policies per se, rather than than on the existence of market interaction. This paper, therefore, shed new light on recycling policy designs under a more realistic market condition by the help a differential game model.

Existing analysis of recycling policy - including Design for Environment (DfE) incentives - are mostly based on a single company model (Chen \& Sheu, 2009; Choe \& Fraser, 2001; Fullerton $\& \mathrm{Wu}, 1998$; Stavins, 2002). From the literature, however, we understand that consequence of incentive behave differently in a multiple companies competition context (Chen \& Sheu, 2009; Dockner et al., 2000), and thus the interactive effect of incentive policies and regulations needs to be reviewed. Moreover, product pricing and manufacturing costs mostly determine the profitability of a firm. Manufacturers accrue their profits by setting the right pricing strategies with consideration for competitor responses and product characteristics (Reijnders, 2003). Among the environmental policy literature, however, while tax or subsidy pricing is often discussed, little attention is given to product pricing and environmental friendly design policy. In recent years, EPR has attracted much attention and the notion of EPR has been part of the concept of green supply chain. According to (Barde \& Stephen, 1997), EPR is defined as a strategy designed to promote the integration of environmental costs of products throughout 
their life cycles into the market distribution mechanism so as to reduce product harm to the environment. A prosperous green supply chain can not be substantiated without the help of proper incentives and public policies (Sheu, 2008). With the implementation of EPR policies in various supply chains, producer responsibilities have been extended from selling products to recycling them, meanwhile pushing waste management issues to upstream manufacturers and even the entire supply chain.

In order to promote the concept of EPR, governments around the globe usually provide financial incentives for manufacturers and encourage them to engage in EPR practices (Palmer \& Walls, 1999). Appropriate incentive mechanisms not only internalize externality by changing the cost structure for producers, but they also drive manufacturers to develop more environmentally friendly products. Moreover, although international prominence has shifted to product sustainability, the subject of product design is still seen as one of the top priorities for governments and manufacturers (Chen et al., 2010). When enterprises respond to strict controls regarding their social responsibility, and at the same time begin to take account of competitive pricing and manufacturing costs, it is often considered difficult for them to determine a long-term profit strategy. Existing literature has pointed out that, however, environmentally friendly designs can reduce material use, enhance business competitiveness, and have other benefits, there is no clear suggestions or practical consideration given as to how and to what extent product design can be improved (Chen et al., 2010).

Effect of EPR incentive on green product design reacts differently from a market with competitors. Member firms in a green supply chain, in every dynamic stage of the decision making process, attempt to estimate the actions of their rivals and then identify what corresponding strategies can be used to drive the firm toward a maximized profit situation. Such strategies, however, are expected to coincide with environmentally friendly design from the views of policy makers. To facilitate this process, we use a differential game model to derive optimal design trajectories and to illustrate how manufacturers can adopt optimal product green design and pricing strategies for pursuing maximal profit whilst also complying with social responsibility.

\section{Literature review and environmental policies}

Growing consensus exists that key members of supply and reverse supply chains should be managed in such a manner that their profits are maximized. Policy instrument issues have been investigated extensively in the environmental economics field (Benchekroun \& Van Long, 2002; Ulph, 1996; Walls \& Palmer, 2001). Along with the growing interest in GSCM by incorporating reverse logistics functionality into an original SCM strategic framework, a comprehensive closed-loop supply chain structure that can address diverse issues is emerging, such as remanufacturing (Mukhopadhyay \& Setaputra, 2007; Spicer \& Johnson, 2004), product recovery and return (Padmanabhan \& Png, 1997), and production-induced waste reprocessing (Tsoulfas et al., 2002).

Moreover, the notion of Design for Environment (DfE) has been suggested (Spicer \& Johnson, 2004; Walls, 2003). The DfE possesses broad coverage (Calcott \& Walls, 2005) and strives to integrate, in a systematic way, various aspects of environment, health, and safety into the design phase of the production process, while at the same time seeking to satisfy simple and easy disassembling design criteria (Calcott \& Walls, 2005; Walls, 2003). Given such broad sentiment, this paper focuses particularly on the recyclability of product green design in the following three areas: ease of disassembly, usage of toxic materials, and reusability of resources (Calcott \& Walls, 2005), i.e., design for recycling (Kriwet et al., 1995). 
The definition of recycling rate has seen a dispute among literature and across country boarders. Implementation of the recycling vary in countries and therefor the definition remains different. In WEEE Act, the recycling rate amounts to the recycled weight percentage with respect to total disposal. It clearly regulates that: (1) the re-use and recycling rate be up to $75 \%$, and (2) the resource recovery rate be up to $80 \%$ of the weight of each recovery (Yamaguchi, 2002). A prevalent definition of recyclability has been known as a rate or percentage of recyclable material in a product composition (Duchin \& Lange, 1994). This definition of recyclability is easy in self-checking for individual producer and has been adopted in this paper.

There are various regulatory and financial incentive schemes. Globalized organizations including Apple, Sony, and Matsushita - invest a large portion of their budgets in DfE activities in order to green their supply chain. The motivation that drives these firms to implement DfE (Walls, 2003) appears to lie in a combination of regulation and production cost (Avila, 2006; Chen et al., 2009; Gottberg et al., 2006; Iliyana, 2006; Palmer \& Walls, 1999). In order to compensate for harm caused by the lack of flexibility in command and control, incentive mechanisms can be a complement to maintaining industry growth (Chen et al., 2009; Jaffe et al., 1995). Under these mechanisms, manufacturers are charged differently according to their product's characteristics in ease of handling (Dinan Terry, 1993; Dobbs, 1991; Fullerton \& $\mathrm{Wu}, 1998)$.

Issues associated with exploiting economic incentives to promote all stages of material recycling have been extensively investigated in the environmental economics field (Benchekroun \& Van Long, 2002; Ulph, 1996; Walls \& Palmer, 2001). Although efforts to collect, recycle, and smelt large amounts of scrap have been exerted, some materials are left behind, generating an unbalanced closed-loop supply chain.

The price discrimination is expected to regulate manufacturers' environmental responsibility effectively. Among existing incentive designs, product charges or taxes are levied against products that causes environmental pollution prior to production to reflect the externality costs (Barde \& Stephen, 1997). We assume that different incentives for firms largely result from differentiated processing fees charged by recycling treatment agencies providing discriminated product recyclability (Duchin \& Lange, 1994). In other words, the fee schemes depend on the total amount of scraps as well as the ease of handling in waste treatment and processing.

Comparing to previous literature, we provide a distinctive feature. We extend mixed incentive strategies to a broader view. This paper finds that, for manufacturers in competition, simultaneously offering financial incentives and increasingly stringent regulation is necessary for promoting green product recyclability.

\section{Competitive differential game model}

In attempting to address the effectiveness of EPR instruments in a competitive environment, our model is built on top of a simplified situation in which an integrated financial incentive and regulation standard is imposed. To manifest the dynamic interaction, and for ease of illustration and analysis, we have constructed a differential game model with sales and recycling dynamics. In our model we assume that, for firms to be environmentally conscious, certain regulation standards need to be imposed to reflect current social responsibility (Foulon et al., 2002). Moreover, a certain amount of capital expenditure also needs to be invested in order to comply with government standards (Cohen, 1999; Foulon et al., 2002).

$x_{i}(t)$ and $\xi_{i}(t)$ represent the market share and recycling rate of producer $i$ at time $t$, respectively. The incentive is incorporated in recycling treatment fee $u_{i}(t)$, which is charged 
by the treatment agency and depends on the product's recyclability involvement $d_{i}(t)$, e.g., the extent of ease of disassembly. To implement a simplified financial incentive in our model, a treatment agency directly charges manufacturers processing fees without involving other third party agencies. In the close-to-real situation, there are other agencies as intermediaries, for example, a Producer Responsibility Organization (PRO) charges EEE manufacturers an amount of fees and establishes a fund to operate the system perpetually. These intermediate third part agencies can be incorporated in the future researches.

To study the competitive behavior, i.e., time trajectories, of firms in a market, we denote the opponents' price decisions and market share as

$$
\begin{aligned}
& p^{-i}(t)=\left(p_{1}(t), p_{2}(t), \ldots, p_{i-1}(t), p_{i+1}(t), \ldots, p_{n}(t)\right), \\
& x^{-i}(t)=\left(x_{1}(t), x_{2}(t), \ldots, x_{i-1}(t), x_{i+1}(t), \ldots, x_{n}(t)\right) .
\end{aligned}
$$

We normalize the market share $x_{i}(t) \in[0,1]$ such that they sum up to unity at any time instance

$$
\sum_{i=1}^{n} x_{i}(t)=1 \text {. }
$$

The sales dynamics can be suitably described by a set of differential equations (1) with the form of Vidale-Wolfe (Prasad \& Sethi, 2004).

$$
\begin{aligned}
\dot{x}_{i}(t) & =f_{x_{i}}\left(x_{i}(t), x^{-i}(t), p(t)\right) \\
& =\sum_{j \neq i} \rho_{j} p_{j}(t) \sqrt{x_{i}(t)}-\sum_{j \neq i} \rho_{i} p_{i}(t) \sqrt{x_{j}(t)}-\delta\left(x_{i}(t)-\sum_{j \neq i} x_{i}(t)\right)
\end{aligned}
$$

All firms determine their product prices at very time instance in order to conquer maximal market shares. Pricing decisions are made by responding competitor reactions of prior price and market share changes. Prices differences between products affect customer purchasing preferences, thereby causing sales and market share deviation. Market share change rate $\dot{x}_{i}$ of firm $i$ in (1) constitutes the influence from its own market share $x_{i}$ and the market share $x_{j}$ of other products.

If manufacturers enhance their green product recyclability design, i.e., the percentage of weight in their products been recycled, their product recycling rate will increase proportionately (Choe \& Fraser, 2001). However, when reviewing EPR policy literature, we found that the definition of the recycling rate between countries is not limited to a specific context.

To relate to the EPR, the responsibility elasticity to unfulfilled recycles (Jalal \& Rogers, 2002) is defined as

$$
\alpha=\frac{\frac{\partial M}{M}}{\frac{\partial \tau}{\tau}}
$$

where $M=1-\sum_{i=1}^{n} \xi_{i}$ represents unfulfilled recyclables, ignored by all manufacturers, and $\tau$ represents producer responsibility in a country. For example, $\alpha=-2$ means unfulfilled waste will decrease $2 \%$ as responsibility increases $1 \%$. Every country may develop different social responsibility levels. This simply reflects the average environmental consciousness and regulation stringency in a particular society.

Let $\xi_{i}(t)$ and $d_{i}(t)$ represent the recycling rate of product $i$ and the recyclability involvement of product $i$, respectively. Motivated by diffusion models in marketing and the consequence of new product sales (Dockner \& Fruchter, 2004), the recycling dynamics can be suitably 
described through (3)

$$
\dot{\xi}_{i}(t)=\left(\eta+\varepsilon_{i} d_{i}(t) / \tau\right) \sqrt{x_{i}(t)}\left(1-\sum_{i=1}^{n} \xi_{i}(t)\right)
$$

The influence of the dynamics of the recycling rate constitutes recyclability, the producer responsibility acting on market share and any unfulfilled recycling weight. The resulting behavior follows an S-shape dynamics. At lower rates of recycling, the improvement appears to be slow. When the recycling rate, however, increases to some extent, it starts to rise dramatically. Eventually, as most of the materials are recyclable, it becomes more difficult to improve the recycling rate.

The above two dynamics collectively describe the behavior of a recycling system in a competitive environment. The sales dynamic points out that when manufacturers commence a price war in the market, sales volume rises in consequence. More sales, however, leads to more waste, so that manufacturers need to take heavier responsibility for recycling (Barde \& Stephen, 1997). In this case, manufacturers may be more willing to engage in product design recyclability in order to alleviate increasing costs.

In order to provide the conceptualization terse and to simplify consequent derivations, we aggregate all $\xi_{i}(t)$ to an single $\tau(t)$ (Dockner \& Fruchter, 2004). By summing up all $\dot{\xi}_{i}$ of (3), the recycling dynamics can be easily transformed to

$$
\alpha \dot{\tau}(t)=-\eta \tau(t)-\sum_{i=1}^{n} \varepsilon_{i} d_{i}(t) \sqrt{x_{i}(t)}
$$

In order to pursue profit maximization, we assume revenue to be solely generated by selling products, while costs are accrued from multiple sources - such as, production cost $w_{i}\left(x_{i}(\cdot)\right)$, production process upgrading cost $h_{i}\left(d_{i}(\cdot)\right)$, recycling fee $u_{i}\left(d_{i}(\cdot)\right)$ paid to the treatment agency, and capital expenditure $n(\tau(\cdot) ; \zeta(\cdot))$ made to comply with the government regulation standard $-\zeta(\cdot)$ (Jaffe et al., 1995). Upgrading costs includes R\&D investment, costs incurred for altering production processes, and costs associated with consuming recyclable materials (Mukhopadhyay \& Setaputra, 2007).

In this paper we assume $n$ is linear in $\zeta \tau$, which represents the environmental regulation standard determined by producer responsibility in a society. The net profit amounts to the difference between sales revenue and all accrued costs and can be written as (5) with the notion of NPV, where $r_{i}$ is the discount rate and assumed to be constant.

$$
J_{i}\left(p_{i}(\cdot), d_{i}(\cdot)\right)=\int_{0}^{T} e^{-r t} F\left(x_{i}(t), \tau(t), p_{i}(t), d_{i}(t), t\right) d t
$$

where

$$
\begin{aligned}
& F\left(x_{i}(t), \tau(t), p_{i}(t), d_{i}(t), t\right)=v_{i}\left(x_{i}(t), p_{i}(t)\right)-c_{i}\left(x_{i}(t), \tau(t), d_{i}(t)\right) \\
& =v_{i}\left(x_{i}(t), p_{i}(t)\right)-w_{i}\left(x_{i}(t)\right)-h_{i}\left(d_{i}(t)\right)-u_{i}\left(x_{i}(t), d_{i}(t)\right)-n_{i}(\tau(t) ; \zeta(t))
\end{aligned}
$$

To keep the problem explicit, some assumptions are imposed regarding to the behavior of manufacturers:

1. We are dealing with a differential game with simultaneous decision making (Dockner et al., 2000). Every player is rational and seeks to maximize their objective functional. 
2. All products are homogeneous but companies are not. Each firm has its own cost structure and ability to attract customers from its competitors.

3. There is only one representative treatment agency and it makes no profit in our system. It offers incentives by charging manufacturers differently according to the level of recyclability.

With the implementation of incentives and regulations, manufacturers constantly ponder how to re-allocate costs more effectively and select suitable recyclability involvement in order to achieve their own profit maximization. With the optimization problem of competing parties, our differential game model solves the Markovian Nash equilibrium. This occurs when a participant in a game speculates the optimal strategy of other participants to find his own optimal strategy. This strategy gives no motivation for all rational participants to deviate from this equilibrium (Dockner et al., 2000).

Let $\phi^{i}\left(x_{i}, \tau, t\right)$ denote a Markovian strategy of producer $i$. A Markovian Nash equilibrium satisfies the Hamilton-Jacobi-Bellman (HJB) equations (6).

$$
\begin{aligned}
r_{i} V_{i}=\max _{p_{i}, d_{i}}\left\{v_{i}\left(x_{i}, p_{i}\right)-c_{i}\left(x_{i}, \tau, d_{i}\right)+\right. \\
\left.V_{i x} \dot{x}\left(x_{i}, x^{-1}, p_{i}\right)+V_{i \tau} \dot{\tau}\left(x_{i}, \tau, d_{i}\right)\right\}, i=1,2,
\end{aligned}
$$

where the notation $V_{i x}$ presents the partial derivative of $V_{i}$ with respect to $x$, i.e., $\partial V_{i} / \partial x$. Expand the HJB (6) to (7)

$$
\begin{aligned}
r_{i} V_{i}=\max \{ & v_{i}\left(x_{i}, p_{i}\right)-h_{i}\left(d_{i}\right)-u_{i}\left(x_{i}, d_{i}\right)-n_{i}(\tau ; \zeta)+ \\
& V_{i x}\left(\rho_{2} p_{2} \sqrt{x}-\rho_{1} p_{1} \sqrt{1-x}-\delta(2 x-1)\right)+ \\
& \left.V_{i \tau} \frac{1}{\alpha}\left(-\eta \tau-\varepsilon_{1} d_{1} \sqrt{x}-\varepsilon_{2} d_{2} \sqrt{1-x}\right)\right\}, i=1,2 .
\end{aligned}
$$

Taking maximization with respect to $p_{i}$ and $d_{i}$ on the right-hand side of (7) yields

$$
\begin{aligned}
\frac{\partial v_{i}}{\partial p_{i}}-V_{i x} \rho_{i} \sqrt{1-x_{i}} & =0 \\
-\frac{\partial h_{i}}{\partial d_{i}}-\frac{\partial u_{i}}{\partial d_{i}}-V_{i \tau} \frac{\varepsilon_{i}}{\alpha} \sqrt{x_{i}} & =0
\end{aligned}
$$

The resulting Markovian Nash equilibriums of (8) and (9) represent the optimal pricing and design strategies for each firms. We further assume that the revenue function $v_{i}\left(x_{i}(\cdot), p_{i}(\cdot)\right)$ is linear in $x_{i}(\cdot)$ and quadratic in $p_{i}(\cdot)$ and the upgrading cost of recyclability design $h_{i}\left(d_{i}(\cdot)\right)$ is quadratic in $d_{i}(\cdot)$ and the processing fee $u_{i}\left(x_{i}(\cdot), d_{i}(\cdot)\right)$ is linear in $\left(1-d_{i}(\cdot)\right) \sqrt{x_{i}(\cdot)}$, and then we have $\frac{\partial h_{i}}{\partial d_{i}}=C_{h_{i}} d_{i}$ and $\frac{\partial u_{i}}{\partial d_{i}}=C_{u_{i}} \sqrt{x_{i}}$.

The Markovian Nash equilibriums follow:

$$
\begin{aligned}
& p_{i}^{*}=\frac{\rho_{i}}{K_{v_{i}}} V_{i x} \sqrt{1-x_{i}} \\
& d_{i}^{*}=\frac{\frac{\varepsilon_{i} V_{i \tau}}{\alpha}+C_{u_{i}}}{C_{h_{i}}} \sqrt{x_{i}} \equiv \mathcal{F}_{i} \sqrt{x_{i}}
\end{aligned}
$$

The HJB condition provides a necessary condition for evaluating the Markovian Nash equilibrium trajectories. In order to explore the sufficient condition in the future research, 
further restrictions with special structure in the cost function are urged to be imposed (cf. Dockner et al. (2000)).

The equilibriums are subgame perfect if they are autonomous (Dockner et al., 2000). From the derivation in the appendix, our solution trajectories are autonomous, that is,

$$
\begin{aligned}
& p_{i}^{*}(t)=\phi_{p_{i}}^{i}\left(x_{i}(t), \tau(t), t\right)=\phi_{p_{i}}^{i}\left(x_{i}(t), \tau(t)\right), \\
& d_{i}^{*}(t)=\phi_{d_{i}}^{i}\left(x_{i}(t), \tau(t), t\right)=\phi_{d_{i}}^{i}\left(x_{i}(t), \tau(t)\right) .
\end{aligned}
$$

Applying the Markovian Nash equilibrium (10) and (11) into the HJB equations (6), we are then able to solve the Markovian Nash equilibriums with the Hamilton-Jacobi (HJ) equations (14).

$$
\begin{aligned}
r_{i} V_{i}= & \left\{v_{i}\left(x_{i}, \phi_{p_{i}}^{i}\left(x_{i}, \tau\right)\right)-c_{i}\left(x_{i}, \tau, \phi_{d_{i}}^{i}\left(x_{i}, \tau\right)\right)\right. \\
& \left.+V_{i x} \dot{x}_{i}\left(x_{i}, x^{-1}, \phi_{p_{i}}^{i}\left(x_{i}, \tau\right)\right)+V_{i \tau} \dot{\tau}\left(x_{i}, \tau, \phi_{d_{i}}^{i}\left(x_{i}, \tau\right)\right)\right\}, \\
& i=1,2 .
\end{aligned}
$$

In a competitive environment, gaining product recyclability is deliberate. A firm often expands its market share by offering prudent price promotion in order not to cause their rivals to fight-back. The small increase in sales gradually costs the manufacture extra fees to process the waste. This excess cost, however, tends to eliminate the benefit of price promotion and give rise to a more conservative promotion strategy. In other words, a producer can choose to sell less in exchange for lower processing fees without engaging in any product design changes, even though an intensive incentive program has been realized in a market.

According to the aforementioned assumption, and for the purpose of illustration, we explicitly set the parameter functions as

$$
\begin{aligned}
v_{1}\left(x, p_{1}\right) & =C_{v_{1}} x+\frac{1}{2} K_{v_{1}} p_{1}^{2}, \\
v_{2}\left(x, p_{1}\right) & =C_{v_{2}}(1-x)+\frac{1}{2} K_{v_{2}} p_{2}^{2}, \\
h_{1}\left(d_{1}\right) & =\frac{1}{2} C_{h_{1}} d_{1}^{2} \\
h_{2}\left(d_{2}\right) & =\frac{1}{2} C_{h_{2}} d_{2}^{2}, \\
u_{1}\left(x, d_{1}\right) & =C_{u_{1}}\left(1-d_{1}\right) \sqrt{x} \\
u_{2}\left(x, d_{2}\right) & =C_{u_{2}}\left(1-d_{2}\right) \sqrt{1-x}, \\
n(\tau ; \zeta) & =E_{n} \zeta \tau .
\end{aligned}
$$

where production costs $w_{1}$ and $w_{2}$ have been merged into the expression of $C_{v_{1}}$ and $C_{v_{2}}$, respectively. Our main problem therefore can be rewritten explicitly as

$$
\begin{aligned}
& \max _{p_{1}, d_{1}} \int_{0}^{\infty} e^{-r t}\left[C_{v_{1}} x+\frac{1}{2} K_{v_{1}} p_{1}^{2}-\frac{1}{2} C_{h_{1}} d_{1}^{2}-C_{u_{1}}\left(1-d_{1}\right) \sqrt{x}-E_{n} \zeta \tau\right] d t \\
& \max _{p_{2}, d_{2}} \int_{0}^{\infty} e^{-r t}\left[C_{v_{2}}(1-x)+\frac{1}{2} K_{v_{2}} p_{2}^{2}-\frac{1}{2} C_{h_{2}} d_{2}^{2}-C_{u_{2}}\left(1-d_{2}\right) \sqrt{1-x}-E_{n} \zeta \tau\right] d t
\end{aligned}
$$

Subject to 


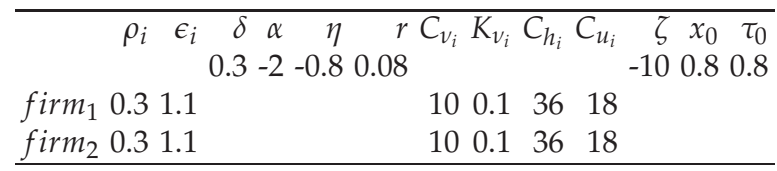

Table 1. Experiment 1: Parameter settings for comparison scenarios.

$$
\begin{aligned}
\dot{x} & =\rho_{2} p_{2} \sqrt{x}-\rho_{1} p_{1} \sqrt{1-x}-\delta(2 x-1) \\
\alpha \dot{\tau} & =-\eta \tau(t)-\varepsilon_{1} d_{1} \sqrt{x}-\varepsilon_{2} d_{2} \sqrt{1-x} \\
x(0) & =x_{0} \\
\tau(0) & =\tau_{0}
\end{aligned}
$$

Proposition 1. For the competition described by (15)-(24), the optimal recyclability in the Markovian Nash equilibrium is a non-decreasing functional of the market share. That is, $\frac{\partial d_{i}^{*}(\cdot)}{\partial x_{i}(\cdot)} \geq 0$.

(Please refer to appendix for proof.)

Under the Markovian Nash equilibrium, the market share trajectories are not necessarily increasing, instead, it follows the sales dynamics controlled by optimal pricing, so that recyclability cannot be guaranteed to be improved. In the case of a market share trajectory not increasing, the government cannot drive producers to a state of higher recyclability without other effective policy. On the other hand, the government can demand all producers take more product responsibility through making the necessary capital investment - for example, production process reconstruction for total waste reduction. This additional expenditure can change the cost structures of manufacturers and force them to reduce costs in other ways, as there is often no room to raise the sales price in a competitive market. In order to meet government standards and take advantage of available incentive programs, a certain degree of product design change needs to be performed - such as easy-disassembly, or increasing the percentage of recyclable components. Observing the behavior of our model, we conjecture that if the government forces producers to adopt a higher standard of responsibility in recycling waste, producers appear to be more environmentally conscious.

Proposition 2. For the competition described by (15)-(24), the optimal recyclability in Markovian Nash equilibrium is a non-decreasing functional of the regulation stringency (negative of $\zeta$ ). That is, $\frac{\partial d_{i}^{*}(\cdot)}{\partial \zeta(\cdot)} \leq 0$

(Please refer to appendix for proof.)

This paper explains the elaborate interaction between market share, pricing and product design. We demonstrate our research findings by two experiments - one comparing the effectiveness of fixed versus increasing policy stringency and the other one showing the performance with various policy stringency. Our propositions can be illustrated and reviewed with the related parameter settings in Table 1. 


\begin{tabular}{lllll}
\hline $\begin{array}{l}\text { Stringent } \\
\text { rate } v_{\zeta}\end{array}$ & Profit $J_{1}$ & Profit $J_{2}$ & $\begin{array}{l}\text { Final } \\
\text { Recyclability } \\
d_{1}^{*}(T)\end{array}$ & $\begin{array}{l}\text { Final } \\
\text { Recyclability } \\
d_{2}^{*}(T)\end{array}$ \\
0.0 & 933 & 931 & 5.96 & 4.21 \\
0.5 & 892 & 896 & 7.03 & 4.95 \\
1.0 & 847 & 859 & 8.09 & 5.69 \\
1.5 & 798 & 821 & 9.16 & 6.43 \\
2.0 & 744 & 780 & 10.2 & 7.16 \\
2.5 & 687 & 738 & 11.3 & 7.90 \\
3.0 & 626 & 693 & 12.3 & 8.64 \\
3.5 & 561 & 647 & 13.4 & 9.38 \\
4.0 & 492 & 599 & 14.5 & 10.1 \\
4.5 & 419 & 549 & 15.5 & 10.8 \\
\hline
\end{tabular}

Table 2. Experiment: Profit and recyclability increase with stringent rates increased.

Based on the parameter settings, the optimal state trajectories follows

$$
\begin{aligned}
\dot{x} & =-\left(\frac{2 \rho_{1} \mathcal{R}_{1} \sqrt{\mathfrak{T}}+2 \rho_{2} \mathcal{R}_{2} \sqrt{\mathcal{T} \mathfrak{X}}}{1+\mathfrak{X}}+2 \delta\right) x+2 \rho_{1} \mathcal{R}_{1} \frac{\sqrt{\mathfrak{T}}}{1+\mathfrak{X}}+\delta, \\
\alpha \dot{\tau} & =-\eta \tau-\left(\varepsilon_{1} \mathcal{F}_{1}-\varepsilon_{2} \mathcal{F}_{2}\right) x-\varepsilon_{2} \mathcal{F}_{2}, \\
x(0) & =x_{0} \\
\tau(0) & =\tau_{0} .
\end{aligned}
$$

In order to manifest the influence of regulation stringency, we conduct an experiment using the parameter set as previous experiment. The Recycling performance changes can be observed by changing the rate of stringency. We let the the regulation standard gradually raised by (28).

$$
\zeta=\zeta_{0}+v_{\zeta}(1-\exp (-t))
$$

The regulation grows with a rate of $v_{\zeta}$. As shown in Table 2 , all parameters remain unchanged in the second experiment and ten levels of rate $v_{\zeta}$ have been employed in this experiment. In spite of profit decreasing as the regulation becomes more stringent, the recyclability of both firms increases significantly. Under this policy, manufacturers are therefore endowed with motivation to enhance their product design.

\section{Conclusions}

This paper is different from existing works in that it analyzes the interactive effects of financial drivers and environmental policies through a dynamic approach. This paper integrates existing differential game models and establishes a novel dynamics analysis that encourages product recyclability. Taking time and competitors' reactions into consideration, the conditions that drive manufacturers to enhance product recyclability have been identified. This paper makes a contribution on the EPR effectiveness issue in a competitive market. Based on the results of this paper, governments should opt to gradually raise regulation standards so that rational manufacturers will implement the corresponding Markovian strategies, i.e., gradually improve its product recyclability. On the other hand, more incentive benefits nevertheless need to be provided where the regulation standard is fixed, in order to urge businesses to achieve the same level of recyclability as in the case of rising standards. 
This conclusion cannot be reached without considering the interactive behavior among competitive firms.

Our results further indicate that governments should consider the effectiveness of environmental policy on the premise that it is nature for business to pursue maximal profits. In order to develop EPR among industries, the first priority of the government should be to enact laws or regulations with rising standards to complement available financial incentive programs. Moreover, to make our differential game model closer to reality, future research can be conducted with other types of treatment agencies, such as Producer Responsibility Organization (PRO), private treatment agencies and the issue of illicit disposal of informal sectors.

\section{Acknowledgment}

This research was supported by grant NSC-94-2211-E-327-006 and NSC-99-2410-H-327-029 from the National Science Council of Taiwan.

\section{References}

Avila, G. (2006). Product development for RoHs and WEEE compliance, Printed Circuit Design and Manufacture 23(5): 28-31.

Barde, J. \& Stephen, S. (1997). Do economic instruments help the environment?, OECD Observer 204: 22-26.

Benchekroun, H. \& Van Long, N. (2002). On the multiplicity of efficiency-inducing tax rules, Economics Letters 76(3): 331-336.

Calcott, P. \& Walls, M. (2005). Waste, recycling, and design for environmentÂÂT: Roles for markets and policy instruments, Resource and Energy Economics 27(4): 287-305.

Chen, Y. J. \& Sheu, J.-B. (2009). Environmental-regulation pricing strategies for green supply chain, Transportation Research Part E: Logistics and Transportation Review 45(5): 667-677.

Chen, Y. J., Wu, D.-H. \& Wu, W.-M. (2010). Effective e-waste management: The role of international cooperation and fragmentation, The 15th International Symposium on Logistics (ISL 2010), Kuala Lumpur, Malaysia, pp. 1-1.

Chen, Y. J., Wu, T.-H. \& Chen, Y.-L. (2009). The recycling business for sustainability in Taiwan, European Business Review 21(5): 403-417.

Choe, C. \& Fraser, I. (2001). On the flexibility of optimal policies for green design, Environmental and Resource Economics 18(4): 367-371.

Cohen, M. (1999). Monitoring and enforcement of environmental policy, International Yearbook of Environmental and Resource Economics 3: 44-106.

Dinan Terry, M. (1993). Economic efficiency effects of alternative policies for reducing waste disposal, Journal of Environmental Economics and Management 25(3): 242-256.

Dobbs, I. (1991). Litter and waste management: Disposal taxes versus user charges, Canadian Journal of Economics 24(1): 221-227.

Dockner, E. \& Fruchter, G. (2004). Dynamic strategic pricing and speed of diffusion, Journal of Optimization Theory and Applications 123(2): 331-348.

Dockner, E., Jørgensen, S., Van Long, N. \& Sorger, G. (2000). Differential Games in Economics and Management Science, Cambridge University Press.

Duchin, F. \& Lange, G. (1994). The Future of the Environment: Ecological Economics and Technological Change, Oxford University Press, USA.

Foulon, J., Lanoie, P. \& Laplante, B. (2002). Incentives for pollution control: Regulation or information?, Journal of Environmental Economics and Management 44(1): 169-187. 
Fullerton, D. \& Wu, W. (1998). Policies for green design, Journal of Environmental Economics and Management 36(2): 131-148.

Gottberg, A., Morris, J., Pollard, S., Mark-Herbert, C. \& Cook, M. (2006). Producer responsibility, waste minimisation and the WEEE directive: Case studies in eco-design from the European lighting sector, Science of the Total Environment, The 359(1-3): 38-56.

Iliyana, H. (2006). RoHs and WEEE-the new European directives: Do they work and why (or why not)? current application and development in the EU and USA, European Environmental Law Review 15(3): 62-74.

Jaffe, A., Peterson, S., Portney, P. \& Stavins, R. (1995). Environmental regulation and the competitiveness of US manufacturing: What does the evidence tell us?, Journal of Economic Literature 33(1): 132-163.

Jalal, K. \& Rogers, P. (2002). Measuring environmental performance in Asia, Ecological Indicators 2(1-2): 39-59.

Kriwet, A., Zussman, E. \& Seliger, G. (1995). Systematic integration of design-for-recycling into product design, International Journal of Production Economics 38(1): 15-22.

Mukhopadhyay, S. K. \& Setaputra, R. (2007). A dynamic model for optimal design quality and return policies, European Journal of Operational Research 18(3): 1144-1154.

Padmanabhan, V. \& Png, I. (1997). Manufacturer's returns policies and retail competition, Marketing Science 16(1): 81-94.

Palmer, K. \& Walls, M. (1999). Extended product responsibility: An economic assessment of alternative policies, Technical report, Resources for the Future, Washington, DC.

Prasad, A. \& Sethi, S. (2004). Competitive advertising under uncertainty: A stochastic differential game approach, Journal of Optimization Theory and Applications 123(1): 163-185.

Reijnders, L. (2003). Policies influencing cleaner production: the role of prices and regulation, Journal of Cleaner Production 11(3): 333-338.

Sheu, J. (2008). Green supply chain management, reverse logistics and nuclear power generation, Transportation Research Part E 44(1): 19-46.

Spicer, A. \& Johnson, M. (2004). Third-party demanufacturing as a solution for extended producer responsibility, Journal of Cleaner Production 12(1): 37-45.

Stavins, R. (2002). Experience with market-based environmental policy instruments, Technical report, Resources for the Future, Washington, DC.

Tsoulfas, G. T., Pappis, C. P. \& Minner, S. (2002). An environmental analysis of the reverse supply chain of SLI batteries, Resources, Conservation and Recycling 36(2): 135-154.

Ulph, A. (1996). Environmental policy instruments and imperfectly competitive international trade, Environmental and Resource Economics 7(4): 333-355.

Walls, M. (2003). The role of economics in extended producer responsibility: Making policy choices and setting policy goals, Technical report, Resources for the Future, Washington, DC.

Walls, M. \& Palmer, K. (2001). Upstream Pollution, Downstream Waste Disposal, and the Design of Comprehensive Environmental Policies, Journal of Environmental Economics and Management 41(1): 94-108.

Yamaguchi, M. (2002). Extended producer responsibility in Japan, ECP Newsletter 10: 1-11. 


\section{A Theorem Proof}

for Proposition 1 in conditions of recyclability. Given the results of (10), apply the function form (15) to (24), the equations (10) and (11) expand to

$$
\begin{aligned}
& p_{1}=\frac{\rho_{1}}{K_{v_{1}}} V_{1 x} \sqrt{1-x} \\
& p_{2}=\frac{\rho_{2}}{K_{v_{2}}} V_{2 x} \sqrt{x} \\
& d_{1}=\frac{\frac{\varepsilon_{1}}{\alpha} V_{1 \tau}+C_{u_{1}}}{C_{h_{1}}} \sqrt{x} \equiv \mathcal{F}_{1} \sqrt{x} \\
& d_{2}=\frac{\frac{\varepsilon_{2}}{\alpha} V_{2 \tau}+C_{u_{2}}}{C_{h_{2}}} \sqrt{1-x} \equiv \mathcal{F}_{2} \sqrt{1-x}
\end{aligned}
$$

Substitute the Markovian strategies (29) to (32) into (7) and then we have the Hamilton-Jacobi equation

$$
\begin{aligned}
r V_{1}= & C_{v_{1}} x-\frac{\rho_{1}^{2}}{2 K_{v_{1}}} V_{1 x}^{2}(1-x)-\frac{1}{2} C_{h_{1}} \mathcal{F}_{1}^{2} x-C_{u_{1}} \mathcal{F}_{1} x-E_{n} \zeta \tau \\
& -\frac{\rho_{2}^{2}}{K_{v_{2}}} V_{1 x} V_{2 x} x-V_{1 x} \delta(2 x-1)-\frac{\eta}{\alpha} V_{1 \tau} \tau-\frac{\varepsilon_{1}}{\alpha} \mathcal{F}_{1} V_{1 \tau} x-\frac{\varepsilon_{2}}{\alpha} \mathcal{F}_{2} V_{1 \tau}(1-x), \\
r V_{2}= & C_{v_{2}}(1-x)-\frac{\rho_{2}^{2}}{2 K_{v_{2}}} V_{2 x}^{2} x-\frac{1}{2} C_{h_{2}} \mathcal{F}_{2}^{2} x-C_{u_{2}} \mathcal{F}_{2} x-E_{n} \zeta \tau \\
& -\frac{\rho_{1}^{2}}{K_{v_{1}}} V_{1 x} V_{2 x}(1-x)-V_{2 x} \delta(2 x-1)-\frac{\eta}{\alpha} V_{2 \tau} \tau-\frac{\varepsilon_{1}}{\alpha} \mathcal{F}_{1} V_{2 \tau} x-\frac{\varepsilon_{2}}{\alpha} \mathcal{F}_{2} V_{2 \tau}(1-x),
\end{aligned}
$$

We conjecture that the value function $V_{i}$ is linear in the state variables(Prasad \& Sethi, 2004).

$$
V_{1}=\mathfrak{A}_{1}+\mathfrak{B}_{1} x+\mathfrak{C}_{1} \tau, \quad V_{2}=\mathfrak{A}_{2}+\mathfrak{B}_{2}(1-x)+\mathfrak{C}_{2} \tau
$$

Therefore $V_{1 x}=\mathfrak{B}_{1}, V_{1 \tau}=\mathfrak{C}_{1}, V_{2 x}=\mathfrak{B}_{2}$ and $V_{2 \tau}=\mathfrak{C}_{2}$. The HJ equations expand to

$$
\begin{aligned}
r \mathfrak{A}_{1} & +r \mathfrak{B}_{1} x+r \mathfrak{C}_{1} \tau=-\frac{\rho_{1}^{2}}{2 K_{v_{1}}} \mathfrak{B}_{1}^{2}+\delta \mathfrak{B}_{1}-\frac{\varepsilon_{2}}{\alpha} \mathcal{F}_{2} \mathfrak{C}_{1} \\
& +\left(\frac{\rho_{1}^{2}}{2 K_{v_{1}}} \mathfrak{B}_{1}^{2}-2 \delta \mathfrak{B}_{1}-\frac{\rho_{2}^{2}}{K_{v_{2}}} \mathfrak{B}_{1} \mathfrak{B}_{2}-\frac{1}{2} C_{h_{1}} \mathcal{F}_{1}^{2}-\left(C_{u_{1}}+\frac{\varepsilon_{1}}{\alpha} \mathfrak{C}_{1}\right) \mathcal{F}_{1}+\frac{\varepsilon_{2}}{\alpha} \mathcal{F}_{2} \mathfrak{C}_{1}+C_{v_{1}}\right) x \\
& +\left(-\frac{\eta}{\alpha} \mathfrak{C}_{1}-E_{n} \zeta\right) \tau, \\
r \mathfrak{A}_{2} & +r \mathfrak{B}_{2} x+r \mathfrak{C}_{2} \tau=-\frac{\rho_{2}^{2}}{2 K_{v_{2}}} \mathfrak{B}_{2}^{2}-\delta \mathfrak{B}_{2}-\frac{\varepsilon_{1}}{\alpha} \mathcal{F}_{1} \mathfrak{C}_{2} \\
& +\left(\frac{\rho_{2}^{2}}{2 K_{v_{2}}} \mathfrak{B}_{2}^{2}+2 \delta \mathfrak{B}_{2}-\frac{\rho_{1}^{2}}{K_{v_{1}}} \mathfrak{B}_{1} \mathfrak{B}_{2}-\frac{1}{2} C_{h_{2}} \mathcal{F}_{2}^{2}-\left(C_{u_{2}}+\frac{\varepsilon_{2}}{\alpha} \mathfrak{C}_{2}\right) \mathcal{F}_{2}+\frac{\varepsilon_{1}}{\alpha} \mathcal{F}_{1} \mathfrak{C}_{2}+C_{v_{2}}\right)(1-x) \\
& +\left(-\frac{\eta}{\alpha} \mathfrak{C}_{2}-E_{n} \zeta\right) \tau .
\end{aligned}
$$


Equating powers of $x$ and $\tau$, some of the unknowns can be easily solved as

$$
\begin{aligned}
& \mathfrak{A}_{1}=-\frac{1}{r}\left(\frac{\rho_{1}^{2}}{2 K_{v_{1}}} \mathfrak{B}_{1}^{2}-\delta \mathfrak{B}_{1}+\frac{\varepsilon_{2}}{\alpha} \mathcal{F}_{2} \mathfrak{C}_{1}\right), \\
& \mathfrak{A}_{2}=-\frac{1}{r}\left(\frac{\rho_{2}^{2}}{2 K_{v_{2}}} \mathfrak{B}_{2}^{2}+\delta \mathfrak{B}_{2}+\frac{\varepsilon_{1}}{\alpha} \mathcal{F}_{1} \mathfrak{C}_{2}\right), \\
& \mathfrak{C}_{1}=\mathfrak{C}_{2}=-\frac{E_{n} \alpha \zeta}{\alpha r+\eta},
\end{aligned}
$$

Let

$$
\begin{aligned}
\mathcal{R}_{1} & =\frac{\rho_{1}^{2}}{2 K_{v_{1}}}, \mathcal{R}_{2}=\frac{\rho_{2}^{2}}{2 K_{v_{2}}}, \\
\mathcal{W} & =r+2 \delta \\
\mathcal{H}_{1} & =\frac{\varepsilon_{1} \zeta}{\alpha r+\eta}, \\
\mathcal{H}_{2} & =\frac{\varepsilon_{2} \zeta}{\alpha r+\eta} \\
z_{1} & =-\frac{3}{2 C_{h_{1}}}\left(C_{u_{1}}-\mathcal{H}_{1}\right)^{2}-\frac{1}{C_{h_{2}}}\left(C_{u_{2}}-\mathcal{H}_{2}\right) \mathcal{H}_{2}+C_{v_{1}}, \\
Z_{2} & =-\frac{3}{2 C_{h_{2}}}\left(C_{u_{2}}-\mathcal{H}_{2}\right)^{2}-\frac{1}{C_{h_{1}}}\left(C_{u_{1}}-\mathcal{H}_{1}\right) \mathcal{H}_{1}+C_{v_{2}} .
\end{aligned}
$$

To solve $\mathfrak{B}_{1}$ and $\mathfrak{B}_{2}$,

$$
\begin{aligned}
\mathcal{R}_{1} \mathfrak{B}_{1}^{2}-\mathcal{W} \mathfrak{B}_{1}-2 \mathcal{R}_{2} \mathfrak{B}_{1} \mathfrak{B}_{2}+z_{1} & =0, \\
-\mathcal{R}_{2} \mathfrak{B}_{2}^{2}-\mathcal{W} \mathfrak{B}_{2}+2 \mathcal{R}_{1} \mathfrak{B}_{1} \mathfrak{B}_{2}+z_{2} & =0,
\end{aligned}
$$

or

$$
\begin{aligned}
& \mathcal{W}\left(\mathfrak{B}_{1}+\mathfrak{B}_{2}\right)^{2}-\left(z_{1}+z_{2}\right)^{2}=0 \\
& \mathcal{R}_{1} \mathfrak{B}_{1}^{2}+\mathcal{R}_{2} \mathfrak{B}_{2}^{2}-2\left(\mathcal{R}_{1}+\mathcal{R}_{2}\right) \mathfrak{B}_{1} \mathfrak{B}_{2}+\left(\mathcal{Z}_{1}-z_{2}\right)=0 .
\end{aligned}
$$

Let

$$
\begin{aligned}
& \mathfrak{B}_{1}=r \cos \theta, \\
& \mathfrak{B}_{2}=r \sin \theta,
\end{aligned}
$$

Applying the parameterization approach, the system of nonlinear equations transforms to

$$
\begin{aligned}
r^{2}(1+\sin 2 \theta) & =\left(\left(z_{1}+z_{2}\right) / \mathcal{W}\right)^{2} \\
r^{2}\left(1+\frac{1}{2} \frac{\mathcal{R}_{2}-\mathcal{R}_{1}}{2 \mathcal{R}_{1}+\mathcal{R}_{2}}(1-\cos 2 \theta)\right) & =\left(\mathcal{R}_{1}+\mathcal{R}_{2}\right)\left(\left(z_{1}+z_{2}\right) / \mathcal{W}\right)^{2}-\left(z_{1}-z_{2}\right) .
\end{aligned}
$$


Set

$$
\begin{aligned}
& \mathcal{S}=\left(\left(z_{1}+z_{2}\right) / \mathcal{W}\right)^{2}, \\
& \mathcal{T}=\left(\mathcal{R}_{1}+\mathcal{R}_{2}\right)\left(\left(z_{1}+z_{2}\right) / \mathcal{W}\right)^{2}-\left(z_{1}-z_{2}\right) .
\end{aligned}
$$

Divide 33 by 34 as

$$
\left(\mathcal{T}^{2 \mathcal{R}_{2}+\mathcal{R}_{1}} \frac{\mathcal{R}}{2 \mathcal{R}_{1}+\mathcal{R}_{2}}-\mathcal{S}\right) \tan ^{2} \theta-2 \mathcal{S} \tan \theta+\mathcal{T}-\mathcal{S}=0
$$

Therefore

$$
\tan \theta=\frac{\mathcal{S} \pm \sqrt{\mathcal{S}^{2}-\left(\mathcal{T}^{2 \mathcal{R}_{2}+\mathcal{R}_{1}} \frac{\mathcal{R}_{1}+\mathcal{R}_{2}}{\mathcal{S}}\right)(\mathcal{T}-\mathcal{S})}}{\mathcal{T}_{\frac{2 \mathcal{R}_{2}+\mathcal{R}_{1}}{2 \mathcal{R}_{1}+\mathcal{R}_{2}}-\mathcal{S}}} \equiv \mathfrak{X}
$$

and

$$
r= \pm \sqrt{\frac{\mathcal{T}}{1+\sin 2 \tan ^{-1} \mathfrak{X}}}= \pm \sqrt{\frac{\mathcal{T}\left(1+\mathfrak{X}^{2}\right)}{(1+\mathfrak{X})^{2}}}
$$

Transform back to $\mathfrak{B}_{1}$ and $\mathfrak{B}_{2}$,

$$
\mathfrak{B}_{1}= \pm \frac{\sqrt{\mathfrak{T}}}{1+\mathfrak{X}^{\prime}}, \quad \mathfrak{B}_{2}= \pm \frac{\sqrt{\mathcal{T X}}}{1+\mathfrak{X}^{\prime}}
$$

The Markov Nash equilibriums follow

$$
\begin{aligned}
& p_{1}^{*}= \pm 2 \mathcal{R}_{1} \frac{\sqrt{\mathcal{T}}}{1+\mathfrak{X}} \sqrt{1-x}, \quad p_{2}^{*}= \pm 2 \mathcal{R}_{2} \frac{\sqrt{\mathcal{T X}}}{1+\mathfrak{X}} \sqrt{x} \\
& d_{1}^{*}=\frac{\frac{E_{n} \varepsilon_{1} \zeta}{\alpha r+\eta}+C_{u_{1}}}{C_{h_{1}}} \sqrt{x} \equiv \mathcal{F}_{1} \sqrt{x} \quad d_{2}^{*}=\frac{\frac{E_{n} \varepsilon_{2} \zeta}{\alpha r+\eta}+C_{u_{2}}}{C_{h_{2}}} \sqrt{1-x} \equiv \mathcal{F}_{2} \sqrt{1-x}
\end{aligned}
$$

Therefore, the derivative of optimal recyclability $d_{i}$ with respect to the market share $x$ becomes

$$
\frac{\partial d_{i}^{*}}{\partial x}=\mathcal{F}_{i} \geq 0
$$

for Proposition 2 with respect to stringency. Follow the results in Proposition 1, the derivative of optimal recyclability $d_{i}$ with respect to $\zeta$ becomes

$$
\frac{\partial d_{i}^{*}}{\partial \zeta}=\frac{E_{n} \varepsilon_{i}}{\alpha r+\eta} \leq 0
$$

since $\alpha, \eta \leq 0$, and $r, E_{n}, \epsilon_{i} \geq 0$. 


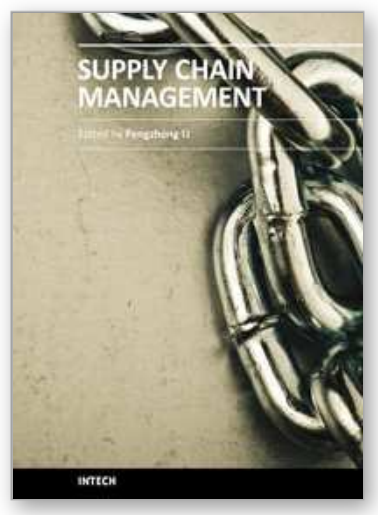

\section{Supply Chain Management}

Edited by Dr. pengzhong Li

ISBN 978-953-307-184-8

Hard cover, 590 pages

Publisher InTech

Published online 26, April, 2011

Published in print edition April, 2011

The purpose of supply chain management is to make production system manage production process, improve customer satisfaction and reduce total work cost. With indubitable significance, supply chain management attracts extensive attention from businesses and academic scholars. Many important research findings and results had been achieved. Research work of supply chain management involves all activities and processes including planning, coordination, operation, control and optimization of the whole supply chain system. This book presents a collection of recent contributions of new methods and innovative ideas from the worldwide researchers. It is aimed at providing a helpful reference of new ideas, original results and practical experiences regarding this highly up-to-date field for researchers, scientists, engineers and students interested in supply chain management.

\section{How to reference}

In order to correctly reference this scholarly work, feel free to copy and paste the following:

Yenming J Chen and Jiuh-Biing Sheu (2011). Differential Game for Environmental-Regulation in Green Supply Chain, Supply Chain Management, Dr. pengzhong Li (Ed.), ISBN: 978-953-307-184-8, InTech, Available from: http://www.intechopen.com/books/supply-chain-management/differential-game-for-environmental-regulationin-green-supply-chain

\section{INTECH}

open science | open minds

\author{
InTech Europe \\ University Campus STeP Ri \\ Slavka Krautzeka 83/A \\ 51000 Rijeka, Croatia \\ Phone: +385 (51) 770447 \\ Fax: +385 (51) 686166 \\ www.intechopen.com
}

\author{
InTech China \\ Unit 405, Office Block, Hotel Equatorial Shanghai \\ No.65, Yan An Road (West), Shanghai, 200040, China \\ 中国上海市延安西路65号上海国际贵都大饭店办公楼 405 单元 \\ Phone: +86-21-62489820 \\ Fax: +86-21-62489821
}


(C) 2011 The Author(s). Licensee IntechOpen. This chapter is distributed under the terms of the Creative Commons Attribution-NonCommercialShareAlike-3.0 License, which permits use, distribution and reproduction for non-commercial purposes, provided the original is properly cited and derivative works building on this content are distributed under the same license. 